\section{Uso de células-tronco no tratamento de pacientes com miocardiopatia dilatada de diferentes etiologias, associada à ressincronização cardíaca artificial}

\section{Stem cell to treat heart disease in association with artificial cardiac ressyncronization}

\author{
Oswaldo Tadeu Greco ${ }^{1}$ \\ Rafael Lois Greco ${ }^{2}$ \\ Ana Carolina de $\mathrm{Abreu}^{3}$
}

${ }^{1}$ Cardiologista e diretor científico do IMC - São José do Rio Preto-SP. ${ }^{2}$ Estagiário de $2^{\circ}$ ano em Cardiologia do Incor - São Paulo. ${ }^{3}$ Bacharel em Direito, profissional de Pesquisas Clínicas.

\section{Senhor Editor}

Apesar do constante desenvolvimento de novas estratégias farmacológicas, condutas eletrofisiológicas com modernos equipamentos e alternativas cirúrgicas cada vez mais sofisticadas, ainda têm as doenças cardíacas altos índices de mortalidade em todo mundo, principalmente devido às miocardiopatias dilatadas, seja de etiologia chagásica, seja de etiologia idiopática ou isquêmica. Esta principalmente como seqüela de um episódio agudo não tratado em seu devido momento, que freqüentemente provoca episódios crônicos de insuficiência cardíaca, refratária a todos os tipos de conduta já anteriormente citados. Este tipo de paciente tem sido muito beneficiado com recentes estratégias de reperfusão miocárdica precoce que promovem um salvamente do miocárdio em risco, reduzindo significantemente as taxas de mortalidade neste grupo, mas, mesmo assim, a incidência de insuficiência cardíaca pós-infarto permanece elevada, principalmente em pacientes diabéticos com irrigação periférica pobre. Recentes estudos têm mostrado que a infusão de células-tronco autólogas de medula óssea por infusão intracoronária ou intramiocárdica tem sido uma possível estratégia para a reversão de disfunção ventricular principalmente pós-infarto, com a regeneração dos miócitos cardíacos, assim como a estimulação da neovascularização na área infartada, com melhora da perfusão na área isquêmica crônica e aumento da função sistólica do ventrículo esquerdo. ${ }^{1}$

Entretanto, além desta área de fibrose que compromete a função cardíaca, existe associado um defeito elétrico, consistindo então em uma causa eletromecânica para esta grave disfunção ventricular.

A proposta é que, para a correção mecânica, exista uma infusão de células-tronco, e, para a correção elétrica, a ressincronização cardíaca artificial, já que estes pacientes têm em comum uma assincronia ou dissincronia intraventricular esquerda ou interventricular direito/esquerdo, provocando im- portante disfunção sistólica com queda significativa da fração de ejeção do ventrículo esquerdo.

Baseando-se nestas informações básicas relacionadas à disfunção ventricular de miocardiopatias dilatadas crônicas, selecionadas pela eletrocardiografia convencional, ergo-espirometria, ecocardiografia, estudo hemodinâmico e com uso da medicina nuclear, na avaliação da análise de fase/amplitude (Gated), do Sestamibi e do MIBG, pudemos selecionar no IMC (Instituto de Moléstias Cardiovasculares) de São José do Rio Preto, estado de São Paulo, Brasil, em um trabalho conjunto do Setor de Marcapasso e do Setor de Terapia Celular, nestes últimos 24 meses (abril 2005/abril 2007), 23 pacientes (21 homens e 2 mulheres), idade entre 43 e 77 anos (média 61 anos), sendo oito chagásicos, cinco idiopáticos e dez isquêmicos. Destes, 13 pacientes receberam células-tronco por via intracoronária e dez, por via intramiocárdica. Além disto, 11 pacientes tiveram seu ressincronizador implantado por via endocárdica e 12 por via epicárdica.

Três pacientes tiveram seu ressincronizador implantado associado a cardiodesfibrilador, devido a arritmia ventricular maligna

Neste período de evolução temos observado, comparando-se resultados de exames já mencionados, o pré com o pós-operatório tardio (>12 meses), melhora da classe funcional (IV/II), da fração de ejeção no ecocardiograma, no Gated, além da sincronia de VE e VD/VE, no estudo hemodinâmico. Um fato interessante também deve ser mencionado: a melhora da população de receptores adrenérgicos obtidos pelo MIBG, coincidente e proporcional com a melhora clínica do paciente e a possibilidade no aumento das doses de carvedilol. Entretanto, autores como Woo e cols. têm mostrado que a magnitude de benefícios foi maior em pacientes com miocardiopatia não isquêmica, em particular na melhora da fração de ejeção e na redução dos volumes do ventrículo esquerdo após a ressincronização cardíaca. A etiologia isquêmica da insuficiência cardíaca tem sido identificada como um preditor em potencial de não resposta a este tipo de estimulação cardíaca. ${ }^{2}$

Hummel e cols. acreditam que esta resposta é inversamente proporcional ao tamanho da área de cicatriz provocada pelo infarto, mas também à sua localização, principalmente quando se apresenta na região póstero-lateral do ventrículo esquerdo. ${ }^{3}$

Por isto, nosso grupo tem optado por este tipo de associação no tratamento destes pacientes, já que o uso de células-tronco autólogas tem sido eficaz para o reparo de miocárdio danificado por este tipo de patologia. Vale a pena salientar que a literatura tem chamado a atenção para o fato de que estas células da medula óssea de pacientes mais velhos, com ou sem fatores de risco, como ateroesclerose, possuem menor capacidade de auto-renovação, proliferação, adesão e incorporação às estruturas vasculares, e o uso de células-tronco derivadas de sangue de cordão umbilical humano tem sido apontado como uma das soluções para substituir as células-tronco obtidas da população doente e idosa. ${ }^{4}$ 


\begin{abstract}
In spite of the development of pharmacological strategies, technology and more sophisticated surgical alternatives, incidences of death from cardiopathies remains high throughout the world, in particular in relation to dilated heart disease. Many of these patients benefit from recent strategies of early myocardial perfusion which significantly reduces mortality rates; even so past-infarction heart failure is common. Recent studies have shown that the infusion of autologous stem cells is a possible treatment to reverse ventricular dysfunction. However, frequently there is an associated electrical conduction defect. Thus, an infusion of stem cells may produce a mechanical correction with heart resynchronization correcting the electrical conduction defect thereby improving the left ventricle ejection fraction. Our institution has been combining stem cell transplantation with resynchronization and, when necessary, cardiofibrilation, to treat these patients giving improvements in the Functional Class, ejection fraction and left ventricle and right ventricle-left ventricle synchrony. Rev. bras. hematol. hemoter. 2007;29(4):421-422.
\end{abstract}

Key words: Dilated heart disease; stem cell transplantation, heart resynchronization; myocardial infarction.

\section{Referências Bibliográficas}

1. Birgt AB, Honold J, Volker S, Martina BB, Ulrich F, Rasokat RL et al. Transcoronary transplantation of progenitor cells after myocardial infarction. N. Engl Med, 2006;355:1222-32.

2. Woo GW, Petersen-Stejskal S, Johnson JW, Conti JB, Aranda JA Jr, Curtis AB. Ventricular reverse remodeling and 6-month outcomes in patients receiving cardiac resynchronization therapy: analysis of the MIRACLE study. J. Interv Card Electrophysiol 2005;12:107-13.

3. Hummel JP, Lindner JR, Belcik JT, Ferguson JD, Mangrum JM, Bergin JD et al. Extent of myocardial viability predicts response to biventricular pacing in ischaemic cardiomyopathy. Heart Rhythm 2005;2:1211-7.

4. Heening RJ, Abu-ali H, Balis JU, Morgan MB, Willing AE, Sanberg PR. Human umbilical cord blood mononuclear cells for the treatment of acute myocardial infarction. Cells Transplant. 2004;13(7-8):729-39.

Avaliação: Editor e dois revisores externos

Conflito de interesse: não declarado

Recebido: 26/04/2007

Aceito após modificações: 10/05/2007

Correspondência: Oswaldo Tadeu Greco

Rua Castelo D'agua, 3.030 - Vila Redentora

15100-000 - São José do Rio Preto-SP - Brasil

E-mail: oswaldogreco@terra.com.br

\section{Gemcitabina e ifosfamida no tratamento do linfoma de Hodgkin refratário ou recidivado após múltiplas terapias}
Gemcitabine and ifosfamide in the treatment of Hodgkin's lymphoma refractory to or relapsed after multiple therapies

\author{
Luís Fernando Pracchia ${ }^{1}$ \\ Camila C.G. Linardi ${ }^{1}$ \\ Valeria Buccheri ${ }^{1}$
}

${ }^{1}$ Serviço de Hematologia - Hospital das Clínicas da Universidade de São Paulo, SP, Brasil

\section{Senhor Editor,}

O tratamento do LH recidivado ou refratário a múltiplas terapias ( $\mathrm{LHr}$ ) é considerado um desafio, principalmente pela exposição prévia do paciente a vários agentes quimioterápicos. Além disso, em nosso país, devido à indisponibilidade de algumas drogas citostáticas, como a mostarda nitrogenada e a procarbazina, existe dificuldade para a utilização de esquemas terapêuticos eficazes em casos de LHr. $\mathrm{Na}$ busca de novas alternativas para o resgate do LHr em nosso serviço, optamos pelo uso compassivo da associação de gemcitabina com ifosfamida (GEM/IFM), para o tratamento ambulatorial do LHr. Esta opção foi baseada na conhecida ação desses dois medicamentos, quando utilizados isoladamente, em casos de LH refratários ou recidivados.

Avaliamos retrospectivamente 17 pacientes consecutivos, portadores de LHr, tratados com GEM/IFM no período de setembro de 2000 a julho de 2004. O tratamento foi composto por seis a oito ciclos de gemcitabina $\left(1,0 \mathrm{~g} / \mathrm{m}^{2} \mathrm{D} 1 \mathrm{e} \mathrm{D} 8\right)$ e ifosfamida (1,0g/m² D1 a D5) administrados a cada 21 dias. Todos os pacientes consentiram com o tratamento antes de seu início e todos foram classificados de acordo com o sistema de estádios de Ann Arbor modificado em Cotswolds. A avaliação de resposta ao tratamento foi obtida através de exame clínico realizado após cada ciclo e de exames tomográficos após cada dois ciclos e avaliada de acordo com os critérios de Cotswolds. Análise de sobrevida foi efetuada pelo método de Kaplan-Meier.

Dos 17 pacientes avaliados, oito (47\%) apresentavam doença em estádio avançado, cinco (30\%) referiam sintomas B e sete (41\%) apresentavam lesão bulky (Tabela 1). Todos os pacientes já haviam sido tratados com pelo menos dois esquemas quimioterápicos prévios, incluindo a terapia de primeira linha com ABVD ou MOPP-ABV, e terapias de resgate com diversos esquemas de segunda linha. 